\title{
Cold-climate Greenhouse and Food Waste Digester
}

\section{Dr. Susan E. Powers, Clarkson University}

Susan E. Powers is the Spence Professor of Sustainable Environmental Systems and the Associate Director of Sustainability in the Institute for a Sustainable Environment at Clarkson University. Dr. Powers is using her current academic position to promote project-based learning experiences to promote sustainability for college students. She is working with several student groups to analyze and improve existing campus operations and design and innovate new facilities to reduce our campus' impact on the environment and society. The goal in all of these projects is to provide real-world, messy and open ended projects to students to enhance their education both in technical aspects as well as team work, communication and integrating sustainability as a critical project criterion.

Prof. Stefan J. Grimberg P.E., Clarkson University 


\title{
Cold-climate Greenhouse and Food Waste Digester Provide Education and Research Opportunities While Greening the Campus
}

\author{
Susan E. Powers, PhD, PE and Stefan Grimberg, PhD, PE \\ Clarkson University, Potsdam NY
}

\begin{abstract}
A new pilot-scale greenhouse, energy cabin and food waste anaerobic digester on our campus enable students to research and explore new technologies for integrating food production and energy recovery from food waste. The greenhouse utilizes innovative technologies and control systems for the year-round production of leafy green vegetables, herbs and tomatoes. The integration of the food production and food waste management components provides closed-loop cycling of many energy and material flows.
\end{abstract}

The system has been integrated into a wide variety of student-led research, class and volunteer projects. These systems are part of our University's efforts to provide experiential learning sites on campus for project-based and student-centered professional experiences that are integral to their preparation for further studies or employment. The nature of the student involvement versus the quality of their deliverables and output has been assessed. Research projects (graduate or undergraduate) that include direct on-on-one interaction with a faculty advisor have generated the highest quality work - though this approach is also time intensive and not sustainable. Integrating this system into senior capstone design classes involves more students and is a more realistic model for the real world. Final deliverables from these classes are, however, more varied in their quality.

\section{Introduction}

The use of on-campus facilities as an integral component of education is a growing trend, ${ }^{1}$ especially to engage students in systems that are designed to improve the sustainability of campus. Today's students care and want to be involved in campus sustainability projects. At a national level, the Princeton Review survey indicated that $65 \%$ of respondents said they would value having information about a college's commitment to the environment, with $24 \%$ saying that such information would "very much" impact their decision to apply to or attend the school, ${ }^{2}$ so integrating sustainability in the classroom has become good business for Universities. ${ }^{3}$ At the same time, our graduates need the same rigor and higher-order thinking skills required to tackle the sustainability challenges that our Nation will face over the next several decades. ${ }^{1}$ Indeed, sustainability meets all of the need for interdisciplinary approaches, with ambiguity, imprecision, and complexity characteristics. Experimentation and discovery are keys to producing workable solutions. ${ }^{4}$ Capitalizing on the combination of students' desires, opportunities on a University campus to provide real-world experiential learning sites, and a National need for educating all students with advanced STEM and critical thinking skills, it makes sense to develop campus experiential learning facilities to include campus sustainability systems into classes from many disciplines. ${ }^{5}$

Through a combination of educational initiatives, leftovers from a research project and equipment donation from an alum, Clarkson University has assembled a nearly closed loop 
system for food production and food waste management. The primary system components shown in Figure 1 include a pilot-scale greenhouse designed, constructed and operated by students, a $300 \mathrm{~kg} / \mathrm{d}$ capacity food waste anaerobic digester, and an Energy Cabin, which was donated after research on the air emissions and energy efficiency of this solar thermal/wood pellet boiler system. This system has been integrated into a variety of learning opportunities for our students to explore the technical and operational systems that can improve campus sustainability.

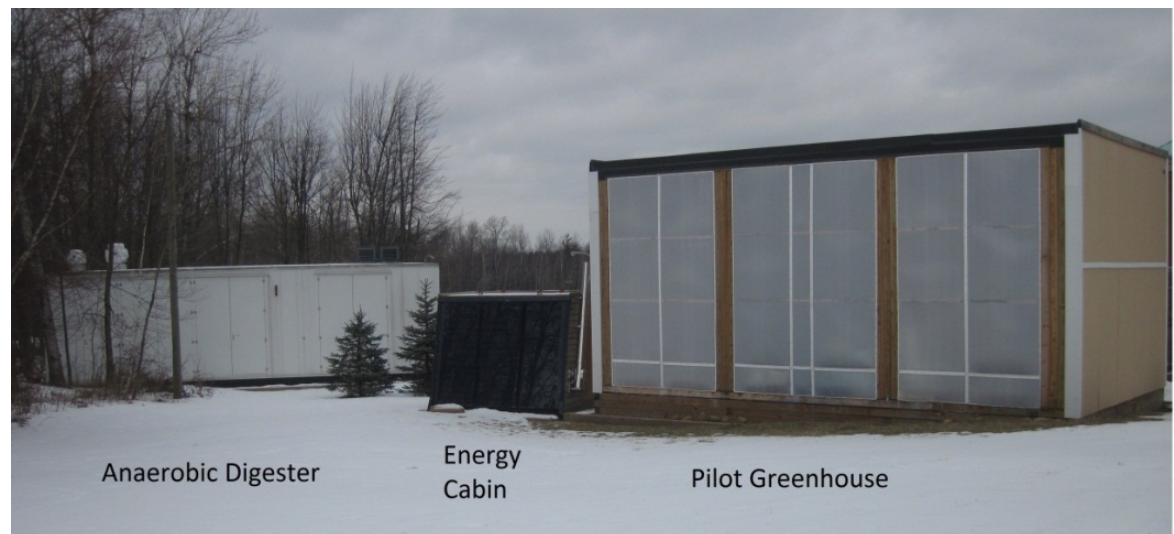

Figure 1: Integrated food production and waste management facility for cold climates

The objectives of this paper are to:

- describe the integrated system components and their implementation for education; and,

- analyze the benefits of this system for developing our students' basic design skills.

\section{Greenhouse Facilities}

A team of students from Clarkson University have proven that they can grow produce year round in an energy, water and space efficient manner, even in the cold and dark climate of northern New York. As petroleum costs increase and shipping produce becomes uneconomical, having the technologies to produce food locally will become increasingly important, even in regions with short growing seasons.

The interdisciplinary project was originally conceived by a Clarkson physics student Daegan Gonyer, now an MS student in Engineering Science. Student teams raised Phase I and Phase II funding for the project in 2009 and 2010 from the EPA through their People, Prosperity and the Planet (P3) student design competition for sustainability. They also conducted laboratory and feasibility studies and did all of the design, construction and operation aspects of the greenhouse and its systems.

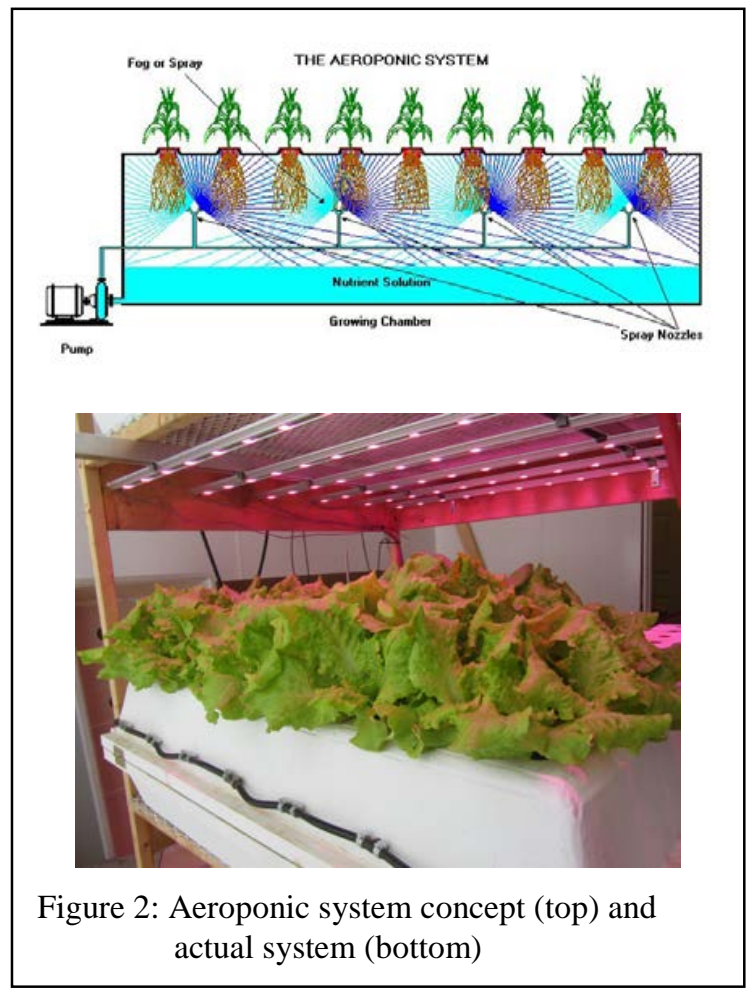



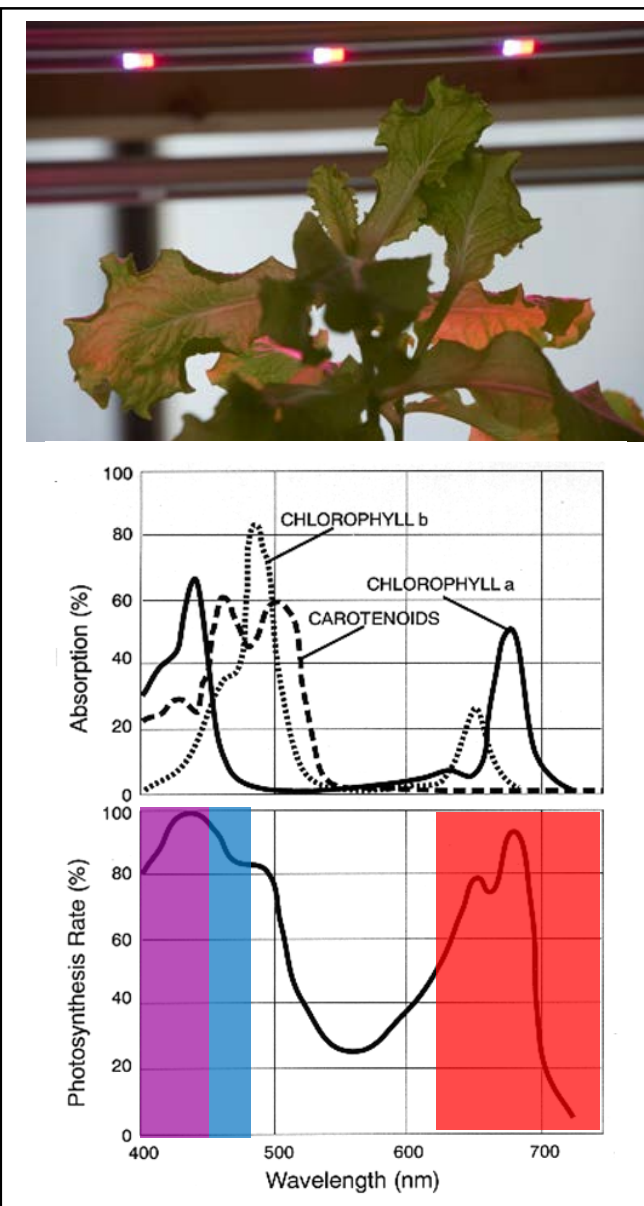

Figure 3: Lighting system for the greenhouse. Actual lights (top) and wavelengths provided (bottom).

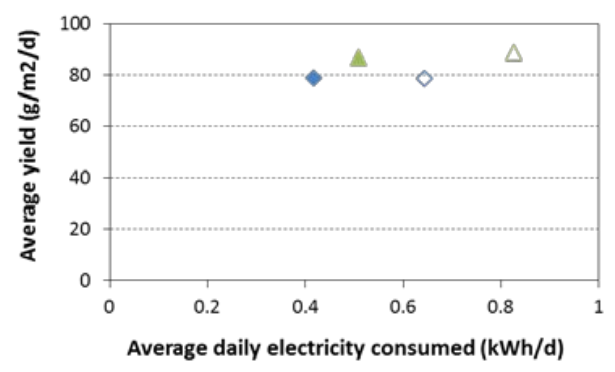

Figure 4: Experimental results show the variation in yield as a function of electricity input for lights averaged over a 38 day experiment. Green triangles are results of two aeroponic units in one room and blue diamonds are for a separate room. The open symbols are the treatments with 12 hours per day of light and the closed symbols are for $10 \mathrm{~h}$. Within each room, there is very little variation in yield between the two light treatments. There is more difference in yields between the rooms than between the light durations. Data are insufficient for statistical analysis
The 450 sq. $\mathrm{ft}$. greenhouse is designed to grow produce year-round in northern climates that are limited by cold and dark winters. The internal heating, LED lighting, and water and plant growth systems are designed to maximize plant growth while limiting fossil fuel energy inputs. The state-of-art aeroponic growing system, in which the plants' roots hang within a closed chamber and are misted periodically (Figure 2), uses only a small fraction of the water and nutrient inputs required by other greenhouse growing operations. The greenhouse was designed with three rooms for testing and experimental design purposes. Two of the rooms are designed for lettuce and the third room for tomatoes.

Because northern climates do not provide sufficient light for plant growth, artificial lighting is also needed. We use high efficiency LED lights that make the rooms glow pink (Figure 3). Plants reflect green light, but they absorb light in the red and blue wavelengths of the visible spectrum. Thus, we can reduce energy use by only providing the light spectra that the plants need. The lighting system is also made more efficient by only providing the light intensity and duration the plants need. Light is measured as the photosynthetic photon flux density (PPFD). Lettuce requires 300 PPFD and tomatoes need 650 PPFD. Light sensors to monitor daylight and a control system are used to turn banks of lights on and off so only enough lights come on to meet plant requirements.

Many different types of plants can grow in an aeroponic system. We have focused on black seeded simpson lettuce to do controlled experiments to improve our processes. Experiments have included variations of nutrient mix (organic concentrated fertilizer used for hydroponic systems or digester effluent), nutrient concentration, light duration and light intensity. We have found, for example, that having light for $10 \mathrm{~h} / \mathrm{d}$ rather than $12 \mathrm{~h} / \mathrm{d}$ does not reduce yield by very much - but it does represent a substantial savings in electricity (Figure 4) 
In addition to providing a great learning opportunity for our students, the pilot greenhouse system has been used extensively for tours and outreach events to promote the role of engineering and business development for the design and implementation of sustainable local food systems (Figure 5).

While the current greenhouse system is functioning, many aspects of the technical design and systems operations need to be improved to make it a viable and sustainable endeavor that provides educational opportunities for our students while generating tasty and safe produce to consume. Examples of

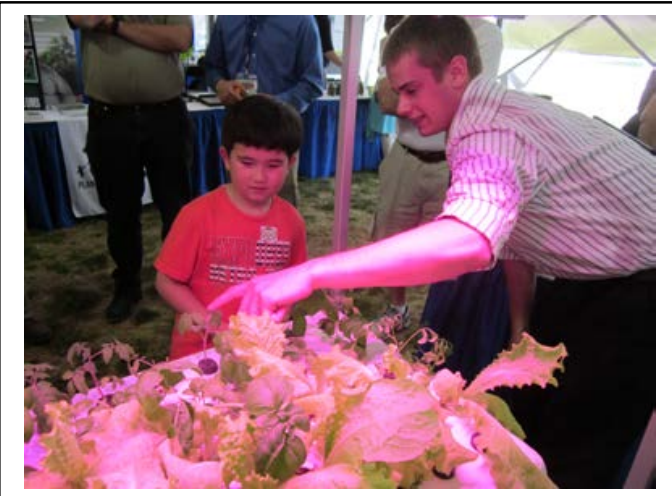

Figure 5: Senior Loren McNamera discusses aeroponics with a child at the 2012 EPA P3 Sustainability Design Competition and Expo projects that are being completed by students include:

- analysis of the energy consumed and cost of heating and powering the system;

- design and installation of shades for the southern wall to reduce heat loss at night and radiant heat gain during the day;

- systems operation plan for timing of seed planting, transplanting and harvesting to maximize yields and potential revenue

- exploration of a broader range of high yield and high value crops that could be grown in an aeroponic system;

- testing of plant yields with new fertilizers recovered from the digester effluent; and,

- modification of the sensor and control system, especially for lighting, to reduce electricity loads.

\section{Anaerobic Digester Facility}

The anaerobic digester system was installed to both manage our food wastes on-site and provide research and education opportunities. The self-contained anaerobic food digester co-generation unit is designed to treat approximately of $300 \mathrm{~kg} /$ day of food waste. It is housed in a shipping




container consisting of three 5,300 L reactors (Figure 6) that can be operated in series or in parallel and an ENI 20kW co-generation combustion engine to produce electricity and heat through burning the produced biogas. The system is completely instrumented allowing for independent operation and remote control. The net result of its implementation is a reduction in the volume of solid waste sent to a landfill, generation of heat and power, and discharge of a nutrient rich effluent that can be used in the greenhouse and on campus grounds.

Since its start up in April 2012, approximately $45 \mathrm{~kg}$ of organic kitchen waste have been fed to the digester per day, which is still only a fraction of the system's capacity. The low mass feed rate during reactor start-up allowed students to familiarize themselves with the basic operation and maintenance of the system without having to handle the total amount of food waste. The material is ground before being pumped into the first stage of a two-phase mesophilic digester operated at a total residence time of 15 to 20 days. Approximately $4.3 \mathrm{~m} / \mathrm{d}$ biogas was produced at a feeding rate of $45 \mathrm{~kg} / \mathrm{d}$ of food waste. Biogas, which consists of $60 \%$ methane and $40 \%$ carbon dioxide, will eventually be used to power a $20 \mathrm{~kW}$ combined heat and power generation system. In case of excess electricity generation the electricity will be available to offset electricity demand of the greenhouse and/or the energy cabin.

Student teams were in charge of the daily operation and analysis of the food waste collection and digester system. Samples were collected manually to characterize the food waste and through the data acquisition system, thereby allowing for the assessment of the efficacy of the individual system components and to optimize the overall process. In the Spring 2013 semester, samples are collected throughout the system in order to assess system performance and optimize the process.

Student involvement in the digester to date has focused primarily on re-engineering an existing system to adapt it to our needs. This has included design and installation of upgrades to the plumbing, wiring and electronic components, and understanding and revising the control system. Other students have worked to characterize the food waste quantity and quality (Figure 7) and work with our campus food services to develop procedures to separate, collect and transfer preconsumer food waste to the digester (Figure 8). Their economic analysis used the concentrations of the food waste collected from one of the campus kitchens and assumed an average reduction of $80 \%$ of the chemical oxygen demand (COD). Extrapolating to full scale use of the digester, they estimated that the system would generate electricity equal to $\$ 15,000$ and avoid $\$ 16,000$ in

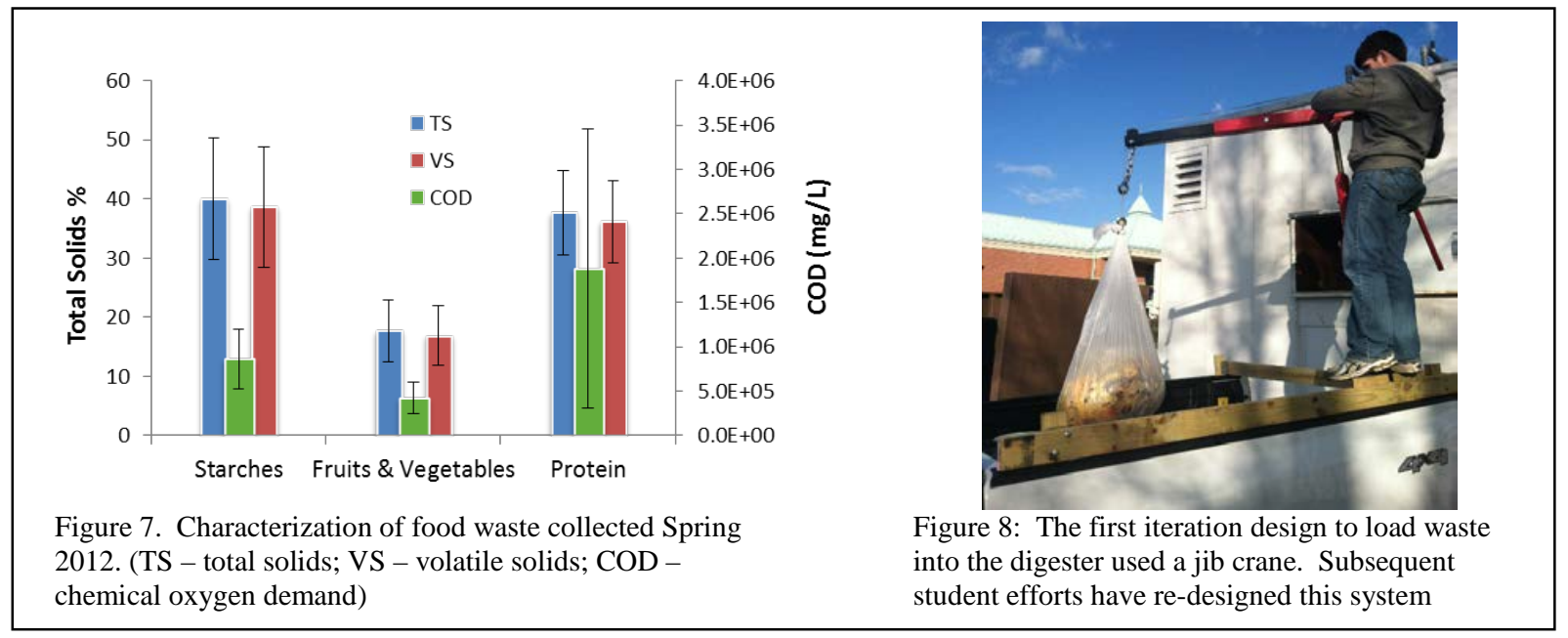


solid waste disposal fees each year resulting in an effective pay-back period of less than eight years if the digester had been purchased.

After one year of improving the basic digester system, the goals of the next capstone design course are to:

- increase treatment of food waste mass flow from $45 \mathrm{~kg}$ to $300 \mathrm{~kg} / \mathrm{d}$;

- quantify biodegradation of food waste throughout the 2-stage system;

- perform a net energy balance around the system operating at steady-state; and,

- initiate operation of the co-generation system producing heat and electricity.

\section{Energy Cabin}

Auxiliary heat for the digester and greenhouse is provided by a wood pellet boiler and solar thermal heating system. ACT Bioenergy of Schenectady, N.Y. supplied this self-contained, integrated heating system that combines a $20 \mathrm{~kW}$ wood pellet boiler with $2 \mathrm{~kW}$ solar-thermal heating panels and integrated hot water storage and control system. The solar thermal system is expected to provide "free" hot water for six months of the year and the pellet boiler will provide the bulk of the hot water during the winter season.

This system was designed and constructed in Europe and arrived in a nearly ready to use condition. Students worked to modify plumbing and electrical systems to connect European (metric and 220 volt) and U.S standard systems. Piping, control systems and heat exchangers were designed and constructed by students to deliver a hot water/glycol mixture from the energy cabin to the greenhouse and digester. Additional sensors were also installed in the energy cabin to assess the efficiency of the system.

Utilizing the Integrated System for Educational Purposes

Many different modes to involve students and promote student learning have been used in the development and operation of this integrated system, including:

- Volunteer efforts

- Paid positions - technician and group leader roles

- Research credits - undergraduates

- Research credits - graduate thesis

- Dedicated capstone design class

- Projects as component in other classes

While a wide range of freshmen through graduate students have been involved in design, construction and operation projects associated with this integrated system, the majority (75\%) of the nearly 100 student participants have received credit for their work through our senior capstone design classes. Students with majors in civil engineering, environmental engineering, mechanical engineering and engineering and management have worked on these projects through the capstone classes. Volunteers and students receiving pay




have included these same majors as well as electrical engineering, computer science and environmental science and engineering majors.

Two capstone design sections have been taught through the Department of Civil \& Environmental Engineering by the authors of this paper. Stefan Grimberg leads the digester group and Susan Powers leads the greenhouse group. Students working on the energy cabin interfaced with both of these sections. Mechanical engineering students have a two-semester capstone experience (6 credits) that includes learning the classic "House of Quality" ${ }^{6}$ design process and understanding the problem and constraints of a particular project in the first semester, with detailed design, implementation and testing in the second semester. All other students receive 3 credits for their capstone design, which is completed in the spring semester of their senior year.

Establishing mechanisms to manage students in these various capacities and teams organized around many different system components is an on-going process. The graduate students are a critical element of the overall group management. They provide greater continuity and a broader perspective of the overall system integration than most of the undergraduate students.

The research and design processes each student group undertakes have evolved over the four years of this project to encompass all steps in a general design process (Figure 8). While all students must begin with some understanding of the problem, some essentially "start from scratch" to ultimately generate original ideas to solve a new problem, while others may start at stages such as "troubleshooting," as they learn about and revising an existing but problematic system component. Many students find the need to back track after initial designs are found to be flawed in some capacity during the "conduct experiments" stage. These iterative loops are represented as dashed lines in Figure 9. The paths taken among these steps may vary greatly depending on the starting point for any particular project. However, most steps are included in some fashion for most projects. A key difference among projects has been the level of detail required in the design, system modeling and implementation. For example, the original feasibility study for the greenhouse addressed many major design decisions (general type of lighting, basic function and geometry of the greenhouse structure), while later groups have designed specific components of sub-systems within the greenhouse or digester (e.g., materials selection and layout of piping systems, motor and pump selection, controls, etc.).

A slightly different version of this spiral has been used in our design classes for years (as adapted from Hacker and Barden ${ }^{7}$ ) to show the general steps associated with engineering design. The words have been changed slightly in the version represented in Figure 9 based on the recent extensive literature review and analysis of engineering design education presented in Crismond and Adams ${ }^{8}$ that emphasizes the differences between novice designers and informed designers. Their informed design teaching and learning matrix was used here to evaluate several of the design reports to ascertain the design proficiency students achieved through their contributions to this real-world campus sustainability system. Table 1 identifies the range of habits exhibited by beginner versus informed designers. 


\begin{tabular}{|c|c|c|}
\hline \multirow[b]{2}{*}{ Design Strategies } & \multicolumn{2}{|c|}{ Novice vs. Informed Designer Patterns } \\
\hline & Novice Designers & Informed Designers \\
\hline $\begin{array}{l}\text { Understand the } \\
\text { Challenge }\end{array}$ & $\begin{array}{l}\text { Treat tasks as well defined, } \\
\text { straightforward problem that they } \\
\text { prematurely attempt to solve }\end{array}$ & $\begin{array}{l}\text { Delay making design in order to explore, } \\
\text { comprehend and frame the problem better }\end{array}$ \\
\hline Build Knowledge & $\begin{array}{l}\text { Skip doing research and instead pose or } \\
\text { build solutions immediately }\end{array}$ & $\begin{array}{l}\text { Do investigation and research to learn about } \\
\text { the problem, how the system works, relevant } \\
\text { cases and prior solutions }\end{array}$ \\
\hline Generate Ideas & $\begin{array}{l}\text { Work with few or just one idea, which } \\
\text { they can get fixated or stuck on and may } \\
\text { not want to change or redirect }\end{array}$ & $\begin{array}{l}\text { Practice idea fluency in order to work with a } \\
\text { lot of ideas by doing divergent thinking, } \\
\text { brainstorming, etc. }\end{array}$ \\
\hline Represent ideas & $\begin{array}{l}\text { Propose superficial ideas that do not } \\
\text { support deep inquiry of a system, and that } \\
\text { would not work if built }\end{array}$ & $\begin{array}{l}\text { Use multiple representations to explore and } \\
\text { investigate design ideas to support deeper } \\
\text { inquiry into how the system works. }\end{array}$ \\
\hline $\begin{array}{l}\text { Weigh options \& make } \\
\text { decisions }\end{array}$ & $\begin{array}{l}\text { Make design decisions without weighing } \\
\text { all of the options, or attend only to pros } \\
\text { of favored ideas and cons of lesser } \\
\text { approaches }\end{array}$ & $\begin{array}{l}\text { Use words and graphics to display and weigh } \\
\text { both benefits and tradeoffs of all ideas before } \\
\text { picking a design }\end{array}$ \\
\hline Conduct Experiments & $\begin{array}{l}\text { Do few or no tests on prototypes or run } \\
\text { confounded tests by changing multiple } \\
\text { variables in a single experiment }\end{array}$ & $\begin{array}{l}\text { Conduct valid experiments on physical } \\
\text { prototypes or through computer simulations } \\
\text { to learn about materials, key design variables } \\
\text { and the how the system works }\end{array}$ \\
\hline Troubleshoot & $\begin{array}{l}\text { Use unfocused, non-analytical way to } \\
\text { view prototypes during testing and } \\
\text { troubleshooting of ideas. }\end{array}$ & $\begin{array}{l}\text { Focus attention on problematic areas in the } \\
\text { subsystem when troubleshooting devices and } \\
\text { proposing ways to fix them. }\end{array}$ \\
\hline Revise/Iterate & $\begin{array}{l}\text { Design in a haphazard ways where little } \\
\text { learning gets done, or do design steps in } \\
\text { linear order }\end{array}$ & $\begin{array}{l}\text { Do design in a managed way, where ideas } \\
\text { are improved iteratively through feedback } \\
\text { and strategies are used multiple times as } \\
\text { needed, in any order }\end{array}$ \\
\hline Reflect on process & $\begin{array}{l}\text { Do tacit designing with little self- } \\
\text { monitoring while working on reflecting } \\
\text { on the process and product when done }\end{array}$ & $\begin{array}{l}\text { Practice reflective thinking by keeping tabs } \\
\text { on design strategies and thinking while } \\
\text { working and after finished }\end{array}$ \\
\hline
\end{tabular}

\section{Analysis of Students’ Design Proficiency}

Eleven reports from the 2010 through 2012 design classes (Table 2) with a range of final grades were evaluated based on this matrix of design strategies. This analysis was completed well after the students completed their work and it did not impact their grade. A score of 10 was assigned for reports that provided evidence of "informed" design skills, with decreasing points assigned for lower levels of proficiency. Scores for the nine design strategies included in this matrix are represented with start plots to provide a graphical interpretation of the strengths and challenges our students have in reaching the "informed" level in this non-traditional capstone class. For the work presented here, there is no comparison group of students in more traditional capstone classes to evaluate how students working with this real-world system compare. 
Table 2: Description of reports analyze for design proficiency

\begin{tabular}{|c|c|c|}
\hline Year & Component & Comments / Scope \\
\hline S10 & Greenhouse structure & $\begin{array}{l}\text { Masters of Engineering design report. Defined greenhouse structure - materials to } \\
\text { enhance passive solar attributes and structural analysis }\end{array}$ \\
\hline F10 & Sensor and control & $\begin{array}{l}\text { Mech. E. design report - developed and implemented overall greenhouse sensor } \\
\text { and control system }\end{array}$ \\
\hline S11 & Greenhouse heating & $\begin{array}{l}\text { Mech. E. design report - designed and constructed hot water radiator system in } \\
\text { greenhouse based on ASHRAE heating model }\end{array}$ \\
\hline S11 & Aeroponic stands & $\begin{array}{l}\text { Designed and constructed a two-level frame to hold aeroponic tanks and provide } \\
\text { fixture for lights }\end{array}$ \\
\hline S12 & Energy cabin & $\begin{array}{l}\text { Designed and installed piping and valve system to transport hot water/glycol } \\
\text { mixture from energy cabin to greenhouse and digester. Needed to integrate design } \\
\text { with existing pumps and heating systems among components. }\end{array}$ \\
\hline S12 & Ventilation & $\begin{array}{l}\text { Mech. E. design report - Designed and built a system to prevent solar radiation } \\
\text { gains from overheating the greenhouse. }\end{array}$ \\
\hline S12 & Thermal shield & $\begin{array}{l}\text { Mech. E. design report - Designed a system to reduce thermal losses through the } \\
\text { southern wall of the greenhouse. Final design was complicated and expensive; the } \\
\text { design was not implemented. }\end{array}$ \\
\hline S12 & Thermal storage & $\begin{array}{l}\text { Mech. E. design report - Designed system to capture and store extra solar radiant } \\
\text { gain in the greenhouse. Final design was complicated and expensive; the design } \\
\text { was not implemented. }\end{array}$ \\
\hline S12 & Water - tomato room & $\begin{array}{l}\text { Reviewed water storage, piping and spraying systems in existing systems to } \\
\text { design and implement better system for the tomato room }\end{array}$ \\
\hline S12 & Water - rain barrels & $\begin{array}{l}\text { Developed design and plan to capture rainwater from greenhouse roof to make it } \\
\text { readily available for greenhouse operations. Student failed to include shipping } \\
\text { costs and implementation of expensive project was not completed. }\end{array}$ \\
\hline S12 & Tomato Lighting & $\begin{array}{l}\text { Students analyzed lighting system in lettuce rooms and designed and implemented } \\
\text { a system to move lights vertically as tomatoes grow }\end{array}$ \\
\hline
\end{tabular}

Results of the analysis of these eleven reports are included in Figure 10. An additional plot that shows the average score among all reports is also included. Each of the axes on these star plots represents the score $(0-10)$ for each of the nine design strategies defined in Table 1.

Based on a general comparison of these shapes, the following general observations can be made:

- Students in the two-semester mechanical engineering design class (red shapes) were more proficient in their design strategies than other students in the one-semester capstone class.

- The graduate student completing his ME design report for this project had more advanced skills than the undergraduate (non-mechanical engineering) students.

- There is a wide variability in students' overall design proficiency and their strengths and weaknesses.

- Some students just don’t care (Energy Cabin example), and virtually no mix of exciting project and good teaching can help develop these students into informed designers.

While this analysis does not include all of the benefits possible with the real-world campus sustainability system, it does address a critical need to develop design skills in our students. The results indicate the potentially high level of design experience that this project can provide given sufficient time. The students in the two-semester mechanical engineering design class clearly accomplished more and had fewer time constraints to fully assess the problem, develop multiple ideas as potential solutions and evaluate these ideas to make well-informed engineering design decisions. This finding suggests the need to expand the duration of the capstone experience for students in other engineering majors or develop specific projects that have a more limited scope and can be completed in a more comprehensive fashion in the allotted time. 
The lack of any outstanding strength or weakness suggests that there is no systemic deficiency in our students' design proficiency. Thus, there does not seem to be any one particular step in the process that needs additional development. The average scores for each design strategy (5.4 7.4) suggest that significant improvement can be made in the students' depth of informed design. The highest average was for the design strategy - "build knowledge" - which is not surprising; the students are very comfortable searching for and interpreting information in this web-based world. Lowest average scores were for "generating ideas" and "weighing options to make an informed choice.” Many students fall into the novice design pitfall of deciding on a solution early - often before they fully understand the problem and constraints - and then latching onto that idea rather than exploring and evaluating other options.

As described by Crismond and Adams ${ }^{8}$, understanding these strengths and weaknesses can be used to redesign the design class expectations and pedagogy. Most importantly, increasing the number of intermediate deliverables that provide focus on the process of design can help students move towards informed designers. Specific techniques are available to increase the quality and outcome of brainstorming activities, create divergent thinkers and relax constraints to help generate a broader set of possible solutions. Having students begin their evaluation of various options by creating graphical (qualitative) design charts or matrices to show and explain the pros and cons of each alternative is at least a first step in developing their ability to weigh options and formulate informed design decisions. While our expectations are that seniors about to enter the work force should do a more quantitative assessment, having them complete a qualitative evaluation is better than allowing them to move forward with projects without adequate evaluation. These approaches will be tried in the spring 2013 design classes with the expectation that students' design skills are improved.

\section{Conclusions}

Campus sustainability projects provide an engaging and real-world design experience for engineering students at all levels. Clarkson University has implemented a unique and integrated food production and food waste management facility that supports the campus' sustainability goals while providing students with a "real” design experience. Most students who complete projects related to this system participate in an interdisciplinary senior capstone design class. Each capstone team tackles the design or redesign of a different component that must be integrated into the overall system.

Students' final reports vary greatly in terms of the scope of their specific project and the depth of their engineering design skills. The quality of the design efforts, as represented through their design reports, was assessed using the Informed Design Teaching and Learning Matrix recently developed by Crismond and Adams. ${ }^{8}$ Eleven reports submitted over the past three years were scored against this matrix. Analysis shows that the students are indeed completing most of the basic steps in the design process through the existing greenhouse and digester infrastructure, but their skills range from novice to informed. Students in the two-semester design class scored much higher than students in a one-semester class. The design strategies that students excelled and were challenged by varied greatly among the reports. This could reflect the nature of the particular design challenge they tackled, their design skills, or the time they had to complete the project. 


\section{Acknowledgements}

Funding for this project has been provided by the US EPA P3 Student Sustainability Design Competition and the Dominion Foundation.

Aeroponic stands

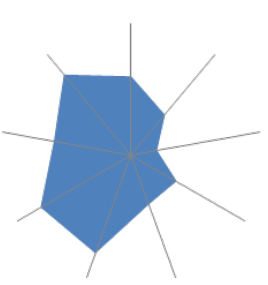

Water-tomato room

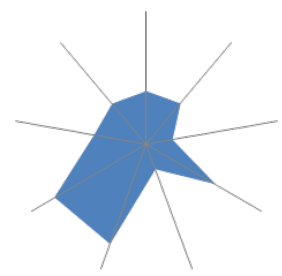

Water - rain barrels

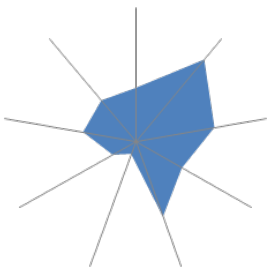

Lighting

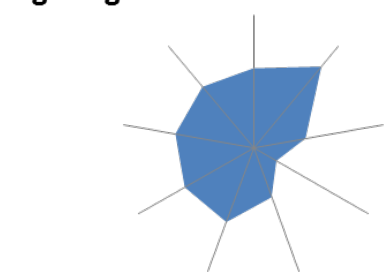

Energy cabin

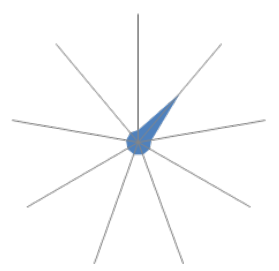

ME structure

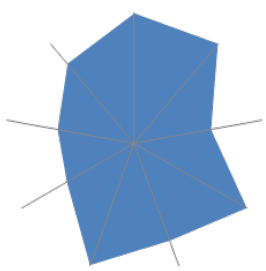

Ventilation

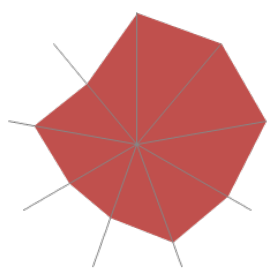

Sensors



Thermal shield

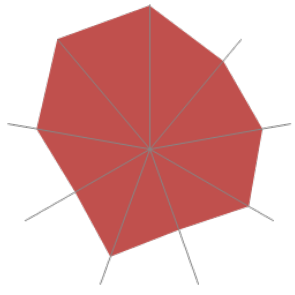

Thermal storage

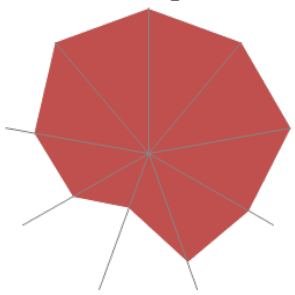

Heating

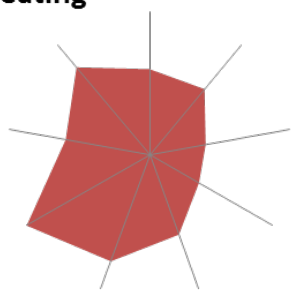

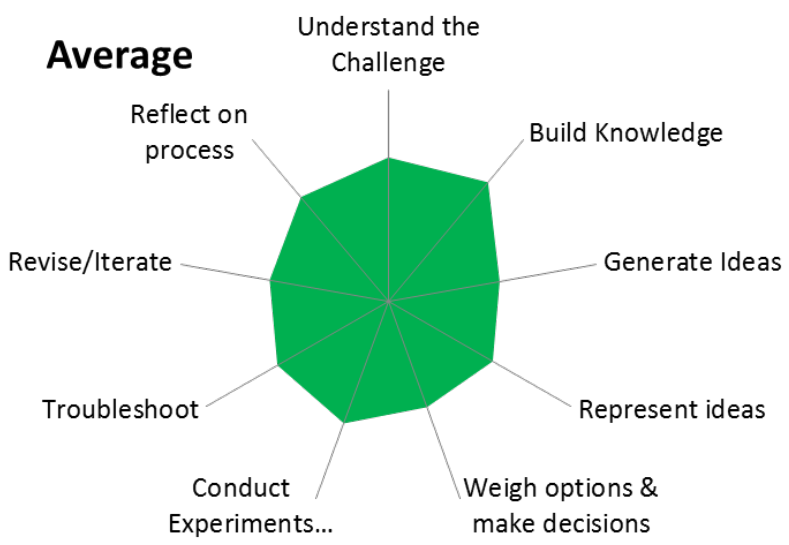

Figure 10: Star plots provide a graphical interpretation of scores for each of the reports analyzed for informed design attributes. A perfect score would be indicated by a nine-sided shape that connects the ends of each axes. The red shapes correspond to students in the two-semester mechanical engineering design class. The green plot proves an average of all scores and also provides labels to define each of the axes. 


\section{References}

1 AASHE, 2010. Sustainability Education in Higher Education: A Call to Action. (accessed 03/12) http://www.aashe.org/files/A_Call_to_Action_final\%282\%29.pdf

2 The Princeton Review's Guide to 322 Green Colleges. Princeton NJ: The Princeton Review, Inc., 2012.

3 --, A business case for developing transformative sustainable education, presented at AASHE 2010 (Pittsburgh PA) < http://www.aashe.org/resources/conference/business-case-developingtransformative-sustainable-education $>$ (accessed 5/22/12)

4 Rhodes, F.H.T., Sustainability: the Ultimate Liberal Art. Chronicle of Higher Education, 53 (9): B24, 2006.

5 Minsker, B. A Framework for Integrating Sustainability Education, Research, Engagement, and Operations through Experiential Learning, presented at AASHE 2011 (Pittsburgh PA) $<$ http://www.aashe.org/resources/conference/framework-integrating-sustainability-educationresearch-engagement-and $>$ (accessed 5/22/12).

6 Hauser, J.R., D. Clausing (1988) The house of quality. Harvard Business Review, May-June, 63-73.

7 Hacker, M., Barden B., Living with Technology, $2^{\text {nd }}$ edition. Delmar Publishers, Albany NY, 1993.

8 Crismond, D.P., R.S. Adams (2012). The Informed Design Teaching and Learning Matrix. Journal of Engineering Education 101(4): 738-797. 